\title{
To Assess the Attitude Regarding Need of Two Wheeler Driving Among Parents of the Late Adolescent
}

\author{
Deeplata M. Mendhe, Priyanka Kurude, Minal Lamsonge, Payal Mahajan, Payal \\ Maheshgawali and Megha Mandawar \\ HOD, Community Health Nursing, SRMM College of Nursing, Sawangi Meghe, Wardha
}

\section{ABSTRACT}

Background: A major proportion of motor vehicles on the Indian roads, especially in metropolitan cities comprise of motorized two-wheelers (Singh, 2012). Indian statistics reveal that two-wheeler riders are amongst the most vulnerable road users and get into road traffic injuries very often; these mostly involve young drivers (Dandona, \& Mishra, 2004; Gururaj, 2005, 2008). Aims- The aim of the study was to assess the attitude regarding need of two wheeler driving among parents of the late adolescent. ".Objective of the study:- 1. To assess the attitude regarding need of two - wheeler driving among parents of late adolescent.2. To associate the score with the demographic variables. Methods and Material: Research approach: Survey approach. Research Design: - Descriptive design. Setting of the study: The study was undertaken in selected rural and urban areas of Wardha.Sample size: 100 Sampling technique: Convenient sampling Results: Majority of samples (48) 48\% were of 38-48 years of age, (60) 60\% were male, educated,(31) 31\% were Graduated, availability of two- wheeler (94)94\% has two- wheeler, parents' monthly income (55)55\% were 10,000-20,000, (68)68\% have two children, source of training (69)69\% by self. Majority of samples 79(79\%) were agree level of attitude score. association of attitude score with the age in year of samples. The 'F' value was calculated 1.146. Also, the calculated 'p' value is 0.334 which was more than acceptable significance level of ' $p$ ' $<0.05$. Therefore, it is interpreted the age in years of attitude regarding the need of two- wheeler driving among the parents is not associated with attitude score.

KEY WORDS: ATTITUDE, TWO WHEELER, LATE ADOLESCENT, PARENTS.

\section{INTRODUCTION}

More than one third of fatal and nearly half of nonfatal road traffic injuries involve two-wheeler riders in India and the majority of the injured are in the age range of 20-30 years (Gururaj \& BRSIPP, 2011). These figures underscore the need to examine various factors implicated in road-safety of two wheeler riding in Indian youth. While behavioural factors such as speeding have been widely recognized as some of the key factors in influencing road traffic accidents (Mehrotra, Sharma EtSudhir, 2008; Dandona, Anil Kumar, \&t Dandona, 2006), there is a paucity of published research on the same in India, especially with reference to young two-wheeler riders. India has been identified by WHO as the worldwide

Biosc Biotech Res Comm P-ISSN: 0974-6455 E-ISSN: 2321-4007

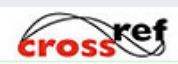

Identifiers and Pagination

Year: 2021 Vol: 14 No (9) Special Issue

Pages: 58-61

This is an open access article under Creative

Commons License Attribn 4.0 Intl (CC-BY). DOI: http://dx.doi.org/10.21786/bbrc/14.9.13 leader in road deaths. Although India has-National speed limit law, National drink-driving law, National motorcycle helmet law, National law on mobile phone use while driving, National drug-driving law, the reported road traffic fatalities in 2010 accounted to 137572 (85\% Males, 15\% Females) as per Transport Research Wing (TRW), Ministry of Road Transport and Highways.

In India WHO estimated road traffic fatalities accounted to 16.6 per 100000 population. Road accidents cost the economy of the country in many respects like infrastructural cost, spending on health care services, compensation as well as rehabilitation of the victims, loss of household services as the economy loses out on the taxes of the earnings of the deceased victims and there is a loss of income for the survivors of the victim's family. RTA's are the leading cause of death for young people aged 15-29. More than a million people die each year on the world's roads and the cost of dealing with the consequences of these road traffic crashes runs to billions of dollars.
Article Information

Received: 05 $5^{\text {th }}$ May 2021 ccepted after revision: $28^{\text {th }}$ June 2021 
Background Of The Study: Motorized two-wheeler riders are one among the most vulnerable Indian road users. However, there is limited research on psychological factors that are likely to influence riding behaviors of youth. The present paper focuses on exploring and documenting emotional states associated with two-wheeler riding in urban Indian youth. The study sampled 1,650 youth, aged between 17-30 years, from 30 educational institutes in Bangalore and Delhi. A Riding Survey developed during the pilot phase was used for data collection. Positive emotional states were commonly reported to be associated with riding and a sense of freedom was one of the commonest factors that were linked to the same, from the perspectives of the youth. Other than commuting, riding for fun (54\%) and riding for relaxation (30\%), relief from boredom (22\%) and getting away from distress (17\%) were endorsed as some of the reasons for taking out the two-wheeler. Seeking a sense of power and control, seeking joy, seeking relief from anger or feeling upset were reported by varying proportions of young riders as some of the reasons for speeding. This exploratory survey highlights an urgent need for addressing the role of emotions in preventive intervention programs that target young two-wheeler riders.

Need Of The Study: As per May 2017 report released by Dainik Bhaskar in Rajasthan, every year 10,000 people die due to road accidents. Among them 35\% are two wheeler riders. This year till March 2017, 2564 people died in road accidents. Among them highest number of deaths are from Jaipur North, Jaipur South, Hanumangarh, Bundi Bara, Chittorgarh and Pali district. In comparison with 2016 report, there is a rise of 83\% in deaths in Hanumangarh and 71\% in Jaipur North. This is an alarming sign, because either people do not have awareness regarding two wheeler rules or do not obey the traffic rules. 3 The United Nations has rightly proclaimed 2011-20 as the Decade of Action on Road Safety. India is a signatory to Brasilia Declaration and is committed to reduce the number of road accidents and fatalities up to 50 percent by 2020 . Simple measures like awareness and practice of two wheeler measures can effectively reduce the impact of RTAs on the lives of people. Hence, the present study aimed to assess the awareness and attitude regarding need of two wheeler driving among the parents of the late adolescent.

Review Of Literature: Review of literature provides the basis for future investigations, justifies the need for replications, justifies the need for replication, and throws light up. On feasibility of the study and indicates constrains of data collection and help to elate the finding of another.

- Review related to importance of two-wheeler in India.

- Review related to attitude regarding need of twowheeler driving.

- Review related to attitude towards speed limits.

- Review related to attitude towards drink driving.
According to Dodona and Mishra, a major proportion of motor vehicles on the Indian.

roads, especially in metropolitan cities comprise motorized two-wheelers (Singh, 2012).Indian statistics reveal that two-wheeler riders are amongst vulnerable road users and get into road traffic injuries very often, these mostly involved young drivers (Dodona and Mishra, 2004; Gujarat, 2005,2008). More than one third of fatal and nearly half of nonfatal road traffic injuries involve two-wheeler riders in India and the majority of injured are in the age range of 20-30 years (Gururaj \& BRSIP, 2011). These figures underscore the 13 need to examine various factors implicated in road-safety of two- wheeler riding in Indian youth.

Conclusion: knowledge does not necessarily translate into improve traffic behavior as was seen in this study. School and college are the basic institution where we can formulate interventions. Continuous reinforcement and education reminding them of traffic rules can bring about a positive change and motivate them to strictly adhere to the traffic norms and help reduce the morbidity and mortality regarding road traffic accident. According to Liu BC, it seems intuitive that helmets should protect against head injuries but it is seen the many two- wheeler users prefer not to used one. A review 61.

observational studies showed that motor cycle helmets were found to reduce the risk of death and head injury in motor cyclists who crashed. From four higher qualities studies helmet were estimated reduce the risk of death by $42 \%$ (or $0.58,95 \%$ CI $0.25-0.38$ ) and from six higher quality studies helmets were estimated to reduce risk of head injury by 69\%. A study was conducted by Carrillo in 1968 to determine whether speed variance contributes to accident involvements on the interstate system. This study way is seen as an extension to the $\mathrm{s}$ difference was that Solomon's study focuses only two and four lane rural highways while Carrillo investigated the contribution of speed variance to accidents in the Interstate system. Carrillo used date collected by 20 state highway departments. Results of the analysis showed that, as the speed of a vehicle varies from mean speed of traffic, the chances of an accident involving the vehicle increase. The involvement rate variation means speed for interstate highways.

A study was conducted on epidemiology of traumatic brain injuries (TBI) IN 2002: Indian scenario" road traffic injuries are the leading cause (60\%) of TBIs followed by falls (20\%-25\%) and violence (10\%). Alcohol investment is known to present among $15 \%$ to $20 \%$ of TBIs at the time of injury. The rehabilitation needs of brain injured persons and significantly high and increasing from year to year. Indian and other developing countries 24 face the major challenges of prevention, pre-hospital care and rehabilitation in their rapidly changing environment to reduce the burden of TBIs.

Problem Statement: To assess the attitude regarding 
need of two wheeler driving among parents of the late adolescent.

\section{Objectives}

- To assess the attitude regarding need of two wheeler driving among parents of the late adolescent.

- To associate the score with the demographic variables.

\section{Operational Defination:}

Attitude:- attitude defined as feeling or opinion about something or someone, or a way of behaving that is caused.

Two wheeler:- A two-wheeler is a vehicle that runs on two wheels.

The two wheels may be arranged in tandem, one behind the other, as with single-track vehicles, or arranged side by side, on the same axle. If on the same axle, the vehicle may be have no other support, as with bicycles, or have additional support, which is often also the source of motive power.

Late adolescent:- The period of development in a person's life from ages 18 to 24 wherein that person becomes a young adult.

Parents :- A parent is a caregiver of the offspring in their own species. In humans, a parent is the caretaker of a child (where "child" refers to offspring, not necessarily age). A biological parent is a person whose gamete resulted in a child.

\section{Hypothesis}

- Ho:- There will be negative attitude regarding need of two wheeler driving among parents of the late adolescent.

- $\quad$ H1 :- There will be positive attitude regarding need of two wheeler driving among parents of the late adolescent.

\section{Variables}

- Independent variable : - Attitude of the parents .

- Dependent variable :- Parents of late adolescents

Assumptions: Parents may have positive attitude regarding need of two wheeler driving in the late adolescent.

\section{RESEARCH METHODOLOGY}

\section{Research approach: - Survey approach}

Research Design: - Descriptive design

Sample:- Parents of late adolescent

Sampling Technique:- Samples will be collected by purposive sampling technique.
Sample size: - The sample size for this study is 100

Setting: - Selected area in Wardha.

\section{Inclusion Criteria:-}

- Parents in selected area who are willing to participate in the study.

- Parents of late adolescent who are available at the time of data collection.

\section{Exclusion criteria}

- Parents of late adolescent who have already attended similar type of study.

Tool: A structured questionnaire will be used for data collection. The questionnaire will be consisting of two sections.

Part 1:- Demographic variable

Part 2:- Likert scale to assess the attitude regarding need of two wheeler drives among parents of the late adolescent.

\section{Interpretation is done based on the following level.}

0-21- Strongly disagree attitude regarding need of twowheeler

21-42- Disagree attitude regarding need of twowheeler

43-63- Neutral attitude regarding need of two-wheeler 64-84- Agree attitude regarding need of two-wheeler

85-105- Strongly agree attitude regarding need of twowheeler

- Validity:- the validity of tool will be established in consultation with guide from community health department.

- Reliability: - reliability assess for the finding of pilot study.

- Pilot study: - pilot study will be conducted on $10 \%$ of the total sample.

- Plan for data analysis: - the collected data will be analyzed by the descriptive and inferential analysis.

Ethical Aspect: Prior approval for the study will be taken from institutional ethical committee. Due permissions will be taken from concerned authorities of the institute where study is to be conducted. Informed and written consent will be taken from the samples and identity of the samples will be kept confidential.

\section{RESULTS}

Distribution of parent's according to the demographic variable: According to age (48) 48\% were of 38-48 years, (40)40\% were of 49-58 years, (10) 10\% were of 59-68 years, and (2)2\% were of 69-78 years. According to gender (60) 60\% were male and (40) 40\% were female. According to education (3) 3\% were Illiterate, (9)9\% were primary educated, (26)26\% were of secondary educated, 
(22)22\% were of higher secondary educated,(31) 31\% were graduated, and (9)9\% were of above graduation. According to availability of two- wheeler (94)94\% has two- wheeler and (6) 6\% doesn't have two- wheeler. According to parents' monthly income (55)55\% were 10,000-20,000, (20)20\% were 20,001-30,000, (12)12\% were 30,001-40,000 and (13)13\% were 40,000 and above. According to number of children in the family (19) $19 \%$ have single child, (68)68\% have two children,(10) 10\% have three children and (3)3\% have more than three. According to the source of training (18)18\% taken training from family,(9) 9\% taken from friends, (4)4\% taken from driving school and (69)69\% by self.

\section{Assess Attitude Score Regarding Need of Two - Wheeler}

Driving Among the Parents of Late Adolescent: 2(2\%) of samples were having disagree level of attitude score, $1(1 \%)$ were neutral level of attitude score, 79(79\%) were agree level of attitude score, $18(18 \%)$ were strongly agree level of attitude score. The minimum score for attitude was 21 and the maximum score for attitude was 93, the mean attitude score was attitude was $75 \pm 9.26$ with a mean percentage of 71.4 .

\begin{abstract}
Association of attitude score with selected demographic variables: Association of attitude score with the age in year of samples. The ' $F$ ' value was calculated 1.146. Also, the calculated 'p' value is 0.334 which was more than acceptable significance level of ' $p$ ' $<0.05$. Therefore, it is interpreted the age in years of attitude regarding the need of two- wheeler driving among the parents is not associated with attitude score.
\end{abstract}

\section{DISCUSSION}

The current study was conducted to assess the attitude regarding need of two- wheeler driving among parents of late adolescent. A detail review of literature indicates aimed to assess the attitude regarding need of twowheeler driving among parents of late adolescent. The findings of the present study show that attitude score of parents of late adolescent is 75. In the present study (2) $2 \%$ of parents is disagree, (1) $1 \%$ of parent is neutral, (79)79\%of parents is agree, and (18)18\% of parents is strongly agreed. There is an association of demographic value with monthly income of parents with the attitude regarding the need of two-wheeler driving.

The results of the present study are consistent with the study of two-wheeler drivers driving towards wearing a helmet, speaking on a cell phone while driving and driving with pillion passengers. Result shows that driving without wearing a helmet on local city road (97)97\% is higher than on highways (89) 89\%. Receive a telephone while travelling on roads (4.30) 4.30\% relative to highways (2.01)2.01\%. Overall cell phone speaking behavior while driving is $(3,02) 3.02 \%$. Driving on city roads with two or more pillion is higher (5.03)5.03\% than on highways. Taking on cell phones after parking on city roads $(1.55 \%)$ as well as on highways $(0.78 \%)$ is a positive overall activity of taking on the cell phones after parking away.

\section{CONCLUSION}

This study leads, after detailed analysis to the following conclusion. The parents of late adolescent were strongly agreed with the attitude regarding need of two-wheeler driving. Attitude of late adolescent parents were categorized into strongly disagreeable, agreed, supportive, agreed and strongly agreed where $2 \%$ of parents disagreed, 1\% of parents were neutral, 79\% of parents agreed and 18\% of parents strongly agreed. The demographic variable like age, gender, education, availability of two-wheeler, parents of monthly income, number of children in family and source of driving training. There is an association of demographic value with monthly income of parents with the attitude regarding the need of two-wheeler driving.

\section{REFERENCES}

A comprehensive review of emerging research on adolescent development can be found in the Handbook on Adolescent Development edited by Lerner and Steinberg (2004). A recent report of a workshop summary from the Board on Children, Youth, and Families, A Study of Interactions: Emerging Issues in the Science of Adolescence (National Research Council and Institute of Medicine, 2006),

Carrillo, JA. (1968). Interstate System Accident Research Study II, Interterm Report II, Interim Report II. Public Roads, Vol. 35, No's.

Dandona, R., \&t Mishra, A. (2004). Deaths due to road traffic crashes in Hyderabad city in India: Need for strengthening surveillance. National Medical Journal of India, 17, 74-79

Dr. Poonam Mittal Aand Dr. Renuka Garg, "A study of behavior of two wheelers drivers towards helmet wearing, talking on cell phone while driving and driving with many pillion riders". May 2013.

Guru raj G. Epidemiology of traumatic brain injuries: Indian scenario Neurology research 2002 Jan; 24(1); 24-28

Lui BC, Invers R, Norton R, Boufous S, et al. (2008) Helmet for preventing Injury in motorcycle Riders. Cochrane Database Syst Rev CD004333.

Ramya MS, Jadhav J, Ranganath TS. A study to determine the awareness and behavioral patterns/practice about road safety measures among undergraduate medical students, Bangalore, India-cross sectional study. International J Community Med Public Health 2017; 4:825-30.

Trivedi A, Rawal D. Prevalence of Road traffic accidents and driving practices among young drivers in Tumkur. 2011; 2(2):72-5. 